\title{
Current Knowledge in Synbiotic Use for Fish Aquaculture: A Review
}

Rebeca Cerezuela, Jose Meseguer and Ma Angeles Esteban*

Fish Innate Immune System Group, Department of Cell Biology and Histology, Faculty of Biology, University of Murcia. 30100 Murcia, Spain

\begin{abstract}
Synbiotics are nutritional supplements that combine probiotics and prebiotics, enhancing their beneficial effects Nowadays, probiotics are also becoming an integral part of aquaculture practices to obtain high production, and, although considerably less information is available regarding probiotics applications for fish, they offer benefits with regards to improving immune status and fish production. Despite the promising potential benefits demonstrated in current literature to these feed ingredients, to date the use of synbiotics in fish farms has been poorly investigated and available data are still scarce. The parameters investigated in these studies have been the following: effect on survival and growth, feed conversion, body composition, haematological/biochemical parameters, digestive enzyme activity, immunological response and disease resistance. This review compiles the results from recent studies, aiming to highlight the properties of synbiotics evaluated for potential application in farming fish. Various factors as fish specie, time of feeding treatment and supplement dose as well as the type of prebiotics and probiotics can significantly affect the activity of synbiotics. Moreover, many aspects such as mechanism which mediate host benefits are poorly understood. Future studies are needed to provide a better knowledge and fully conclude on the effects of adding synbiotics in fish fed.
\end{abstract}

Keywords: Synbiotics; Probiotics; Prebiotics; Fish; Teleosts; Aquaculture

\section{Probiotics and Prebiotics: Concept and Properties}

The use of probiotics and prebiotics has been regarded during recent years as an alternative viable therapy in fish culture, appearing as a promising biological control strategy and becoming as an integral part of the aquaculture practices for improving growth and disease resistance [1]. This strategy offers innumerable advantages to overcome the limitations and side effects of antibiotics and other drugs and also leads to high production [2-5].

Based on the intricate relationship that an aquatic organism has with the external environment when compared with that of terrestrial animals, the definition of a probiotic for aquatic environments needed to be modified or adapted. Probiotics are often defined as applications of entire or component(s) of a micro-organism which are beneficial to the health of the host [6]. Other probiotic definitions are more encompassing, for example, Verschuere et al. [7] suggested the definition "a live microbial adjunct which has a beneficial effect on the host by modifying the host-associated or ambient microbial community, by ensuring improved use of the feed or enhancing its nutritional value, by increase the host response towards disease, or by improving the quality of its environment". Although there is some dispute about what an aquatic probiotic actually is, All definitions differ to that of Fuller [8] in that there is no longer the requisite for the probiotic to be acting in the gastrointestinal tract. Therefore, modes of action such as competition for nutrients and production of inhibitory substances could occur in the culture water. Additional effects of probiotic action should also be considered, given the modified definition, including change of the water quality and interaction with phytoplankton [7].

In aquaculture, the range of probiotics evaluated for use is considerably wider than in terrestrial agriculture. The feasibility and efficacy of a wide range of probiotics for aquatic animals have been investigated in numerous studies, but the best documented are possibly lactic acid bacteria, Bacillus spp. and yeasts [9-11]. Moreover, several probiotics either as monospecies or multispecies supplements are commercially available for aquaculture practices [10].

The success of probiotics has laid the foundation for other concepts as prebiotics. Prebiotics offer an alternative method for manipulating endogenous microbes to improve health. Instead of introducing favourable bacteria with the diet the aim of prebiotics is to stimulate selected favourable indigenous microbial populations [11]. A prebiotic is defined as a non-digestible food ingredient that beneficially affects the host by selectively stimulating the growth and/or the activity of specific health promoting bacteria that can improve the host health [12].

Prebiotics mainly consist of oligosaccharides promoting beneficial bacterial growth within the gastrointestinal tract of higher vertebrates $[13,14]$. In different studies from last ten years, many substances have been investigated as prebiotics. Based on the studies of Mahious and Ollevier [15], Fooks et al. [16] and Gibson et al. [17] any foodstuff that reaches the colon (e.g. non-digestible carbohydrates, some peptides and proteins, as well as certain lipids) is a candidate prebiotic [18]. However, most studies have focused on non-digestible carbohydrates, mainly oligosaccharides. According to Gibson et al. [17], only three oligosaccharides were classified as prebiotics: inulin, transgalactooligosaccharide (TOS) and lactulose. A more recent study includes fructooligosaccharides (FOS) in the list of prebiotics [19]. Mannan oligosaccharides (MOS) and fuctooligosaccharides (FOS, or oligofructose) are perhaps the most well studied oligosaccharides in fish but some information regarding applications of galactooligosaccharides, xylooligosaccharides, arabinoxylooligosaccharides and isomaltooligosaccharides in aquatic animals is also available $[11,20,21]$. Aditionally, inulin, a heterogeneous blend of fructose polysaccharides has also been well regarded in fish [22,23].

In recent years there has been a growing interest in understanding

*Corresponding author: M.A Esteban, Department of Cell Biology, Faculty of Biology, University of Murcia. 30100 Murcia, Spain, Tel: 34-868887665; Fax: 34 868883963; E-mail: aesteban@um.es

Received July 01, 2011; Accepted October 18, 2011; Published October 24, 2011

Citation: Cerezuela R, Meseguer J, Esteban MA (2011) Current Knowledge in Synbiotic Use for Fish Aquaculture: A Review. J Aquac Res Development S1:008. doi:10.4172/2155-9546.S1-008

Copyright: (c) 2011 Cerezuela R, et al.. This is an open-access article distributed under the terms of the Creative Commons Attribution License, which permits unrestricted use, distribution, and reproduction in any medium, provided the original author and source are credited. 
the mechanisms of action of probiotics and prebiotics, especially in humans and other mammals. Probiotics activity is mediated by a variety of effects that are dependent on the probiotic itself, the dosage employed, treatment duration and route and frequency of delivery. Some probiotics exert their beneficial effects by elaborating antibacterial molecules such as bacteriocins that directly inhibit other bacteria or viruses, actively participating in the fight against infections, whereas others inhibit bacterial movement across the gut wall (translocation), enhance the mucosal barrier function by increasing the production of innate immune molecules or modulate the inflammatory/immune response. Several studies have demonstrated that patter recognition receptors [PRRs, such as toll-like receptors (TLRs)], signalling pathways, immune responses and the secretion of antimicrobial peptides such as defensins and chemokines by the epithelium play important roles in these mechanisms [24,25]. On the other hand, potential mechanism of prebiotics includes selective increase/decrease in specific intestinal bacteria that modulate local cytokine and antibody production, increase in intestinal short chain fatty acids production and enhanced binding of these fatty acids to G-coupled protein receptors on leycocytes, interaction with carbohydrate receptors on intestinal epithelial and immune cells, partial absorption resulting in local and systemic contact with the immune system [26].

These alternative methods of disease prevention have been used as a means of reducing the presence of opportunistic pathogens and simultaneously stimulating the host immune responses. However, other effects not immune related have been observed, as improve growth performance, feed utilisation, digestive enzyme activity, antioxidant enzyme activity, gene expression, disease resistance, larval survival, gut morphology, alter the gut microbiota, mediate stress response, improve nutrition, reduce risk of certain cancers (colon, bladder), produce lactase, alleviate symptoms of lactose intolerance and malabsorption $[1,10,11,18,21,27]$.

Despite numerous studies evaluating the efficacy of probiotics and prebiotics in fish, combined application of both additives (synbiotics) has received till present very little attention and available data are still scarce. Therefore, the aim of this review is to compile, for the first time, existing data on the use of synbiotics in aquaculture fish, highlighting the main effects demonstrated to date.

\section{Studies of the administration of synbiotics in fish aquaculture}

Synbiotics refer to nutritional supplements combining probiotics and prebiotics in a form of synergism, hence synbiotics, enhancing their isolated beneficial effects. When two nutritional ingredients or supplements are given together the resulting positive effect generally follows one of three patterns: additivity, synergism or potentiation. Additive effect occurs when the effect of two ingredients used together approximates to the sum of the individual ingredient effects. In case of synergism, it is said to occur when the combined effect of the two products is significantly greater than the sum of the effects of each agent administered alone. The term potentiation is used differently, some pharmacologists use potentiation interchangeably with synergism to describe a greater than additive effect and others use it to describe the effect that is only present when two compounds are concurrently [28].

Synbiotics affects the host by improving the survival and implantation of live microbial dietary supplements in the gastrointestinal tract by selectively stimulating the growth and/or by activating the metabolism of one or a limited number of health promoting bacteria, and thus improving the host "welfare". In humans, probiotics are mainly active in the small intestine while prebiotics are only effective in the large intestine, so the combination of the two may give a synergistic effect [12].

To our knowledge, only five studies so far have investigated the effect of synbiotics in fish (Table 1). In them, probiotics evaluated correspond to two bacterial genera, Enterococcus spp. and Bacillus spp. $[29,30]$, as well as prebiotics FOS and MOS and the studied fish species have been rainbow trout, Japanese flounder, yellow croaker and cobia.

The first application of synbiotics in fish is that of RodriguezEstrada et al. [31]. In this study a commercial preparation of E. faecalis, and two kinds of ingredients, MOS and PHB (a prebiotic included in the group of biopolimers) were used as probiotics and prebiotics, respectively. Seven supplementation protocols were conducted: C) control group, without supplementation; E) supplemented with $1 \%$ E. faecalis; M) supplemented with $0.4 \%$ MOS; P) supplemented with $1 \%$ PHB; EM) supplemented with $1 \%$ E. faecalis and $0.4 \%$ MOS; EP) supplemented with $1 \%$ E. faecalis and $1 \%$ PHP; EMP) supplemented with $1 \%$ E. faecalis, $0.4 \%$ MOS and $1 \%$ PHP.

In the study of Ye et al. [32] diets were supplemented with FOS, MOS and B. clausii alone or in combination. B. clausii strain was previously isolated from grouper (Epinephelus coioides) intestine [33]. The concentrations of the administered supplements in the eight experimental diets were as follows: C) control diet (no FOS, MOS and B. clausii); F) $5 \mathrm{~g} \mathrm{~kg}^{-1} \mathrm{FOS}$; M) $5 \mathrm{~g} \mathrm{~kg}^{-1} \mathrm{MOS}$; FM) $2.5 \mathrm{~g} \mathrm{~kg}^{-1}$ FOS and 2.5 $\mathrm{g} \mathrm{kg}^{-1} \mathrm{MOS}$ ); B) $10^{7}$ cells g-1 B. clausii), FB) $5 \mathrm{~g} \mathrm{~kg}^{-1} \mathrm{FOS}$ and $10^{7}$ cells gB. clausii; MB) $5 \mathrm{~g} \mathrm{~kg}^{-1}$ MOS and $10^{7}$ cells g-1 B. clausii; FMB) $2.5 \mathrm{~g} \mathrm{~kg}^{-1}$ FOS, $2.5 \mathrm{~g} \mathrm{~kg}^{-1}$ MOS and $10^{7}$ cells $\mathrm{g}^{-1}$ B. clausii.

Mehrabi et al. [34] assessed the dietary inclusion of a commercial symbiotic, Biomin IMBO (Biomin, Herzogenburg, Austria), in which was comprised of probiotic (E. faecium $5 \times 10^{11} \mathrm{CFU} / \mathrm{kg}$ ) and FOS as prebiotic, in three levels $\mathrm{T}_{1}=0.5, \mathrm{~T}_{2}=1.0$ and $\mathrm{T}_{3}=1.5 \mathrm{~g}$ into each kilogram of commercial rainbow trout food.

The study of Ai et al. [35] was conducted to evaluate the effects of different concentrations of $B$. subtilis and FOS, combined or separated, on yellow croaker. Nine practical diets were formulated to contain three levels of $B$. subtilis $\left(0.0,0.42 \times 10^{7} \mathrm{cfu} \mathrm{g}^{-1}\right.$ and $\left.1.35 \times 10^{7} \mathrm{cfu} \mathrm{g}^{-1}\right)$, each with three FOS levels ( $0,0.2 \%$ and $0.4 \%$ of dry weight).

The most recent study, conducted in cobia [36] investigated the effects of various levels of dietary B. subtilis and chitosan. Out of the control diet, six different experimental diets containing three graded levels of $B$. subtilis $\left(0.0,1.0,2.0 \mathrm{~g} \mathrm{~kg}^{-1}\right.$ diet $)$ for each of two levels of

\begin{tabular}{lllll}
\hline Fish species & Probiotic & Prebiotic & $\begin{array}{l}\text { Parameters inves- } \\
\text { tigated }\end{array}$ & Reference \\
\hline O. mykiss & E. faecalis & MOS, PHB & GP, BC, IR, HP, DR & $\begin{array}{l}\text { Rodriguez-Estra- } \\
\text { da et al [31] }\end{array}$ \\
P. olivaceus & B. clausii & MOS, FOS & $\begin{array}{l}\text { GP, FU, BC, DEA, } \\
\text { HP, IR }\end{array}$ & Ye et al [32] \\
O. mykiss & E. faecium & FOS & GP, SR, BC, HP & Mehrabi et al [34] \\
L. crocea & B. subtilis & FOS & SR, GP, IR, DR & Ai et al [35] \\
R. canadum & B. subtilis & Chitosan & SR, GP, IR, DR & Geng et al [36]
\end{tabular}

Fish genera abbreviations: O. = Onchorhynchus, P. = Paralichtys, L. = Larimich thys, R. = Rachycentron

Bacterial genera abbreviations: E. = Enterococcus, B. = Bacillus

Prebiotic abbreviations: PHB- plyhydroxybutyrate acid, MOS- Mannan oligosaccharide, FOS- fructooligosaccharide.

Parameters investigated: GP- growth performance, BC- body composition, IR- immunological response, HP- haematological/serum biochemical parameters, DRdisease resistance, FU- feed utilisation, DEA- digestive enzyme activity, SR- survival rate.

Table 1: Summary of fish synbiotic studies. 
chitosan (3.0 and $6.0 \mathrm{~g} \mathrm{~kg}^{-1}$ diet) were prepared for the experimental trial.

All the experimental diets evaluated in the referred studies appeared summarized in Table 2 .

\section{Effects of synbiotics on fish survival rate, growth parameters, feed utilisation and body composition}

All studies conducted to date have evaluated the effects of synbiotics on survival, growth parameters or feed utilisation. Feed cost about over $50 \%$ of the variable costs in most aquaculture operations, therefore applying the best feeding strategy can have a significant impact on optimizing profit, which is the primary goal of commercial aquaculture. Also, if more fish are able to survive until they are of marketable size, the subsequent cost of production would be reduced drastically.

Administration of $E$. faecalis and MOS/PHB in rainbow trout for 12 weeks not affects the survival rate of fish [31]. The experimental fish was healthy and no mortality was observed during the feeding trial. Same occurs in Japanese flounder feeding B. clausii and MOS/FOS, in which fish maintained active ingestion, exhibited proper growth and survived for all time [32].

However, in rainbow trout fingerlings [34], in all synbiotic treatments, test fish were survived significantly in higher rate toward

\begin{tabular}{|c|c|c|c|c|}
\hline Reference & Probiotic/Prebiotic & Diets & $\begin{array}{l}\text { Prebiotic/Probiotic } \\
\text { Concentration }\end{array}$ & Time \\
\hline $\begin{array}{l}\text { Rodriguez- } \\
\text { Estrada et al. } \\
\text { [31] }\end{array}$ & $\begin{array}{l}\text { E. faecalis/MOS, } \\
\text { PHB }\end{array}$ & $\begin{array}{l}\text { C } \\
E \\
M \\
P \\
\text { EM } \\
\text { EP } \\
\text { EMP }\end{array}$ & $\begin{array}{l}0 / 0,0 \\
1 \% / 0,0 \\
0 / 0.4 \%, 0 \\
0 / 0,1 \% \\
1 \% / 0.4 \%, 0 \\
1 \% / 0,1 \% \\
1 \% / 0.4 \%, 1 \%\end{array}$ & 12 weeks \\
\hline Ye et al. [32] & $\begin{array}{l}\text { B. clausii/MOS, } \\
\text { FOS }\end{array}$ & $\begin{array}{l}\text { C } \\
\text { F } \\
\text { M } \\
\text { FM } \\
\text { B } \\
\text { BF } \\
\text { BM } \\
\text { BMF }\end{array}$ & $\begin{array}{l}0 / 0,0 \\
0 / 5 \mathrm{~g} \mathrm{~kg}^{-1}, 0 \\
0 / 0,5 \mathrm{~g} \mathrm{~kg}^{-1} \mathrm{~g} \mathrm{~kg}^{-1} \\
10^{7} \mathrm{cells} \mathrm{g}^{-1} / 5 \mathrm{~g} \mathrm{~kg}^{-1}, 0 \\
10^{7} \mathrm{cells} \mathrm{g}^{-1} / 5 \mathrm{~g} \mathrm{~kg}^{-1}, 5 \\
0 / 5 \mathrm{~g} \mathrm{~kg}^{-1}, 5 \mathrm{~g} \mathrm{~kg}^{-1} \\
10^{7} \mathrm{cells} \mathrm{g}^{-1} / 0,0 \\
10^{7} \mathrm{cells} \mathrm{g}^{-1} / 0,5 \mathrm{~g} \mathrm{~kg}^{-1}\end{array}$ & 56 days \\
\hline $\begin{array}{l}\text { Mehrabi et al. } \\
\text { [34] }\end{array}$ & $\begin{array}{l}\text { Biomin IMBO } \\
\text { (E. faecium/FOS) }\end{array}$ & $\begin{array}{l}\mathrm{T}_{1} \\
\mathrm{~T}_{2} \\
\mathrm{~T}_{3}\end{array}$ & $\begin{array}{l}0.5 \mathrm{~g} \mathrm{~kg}^{-1} \\
1 \mathrm{~g} \mathrm{~kg}^{-1} \\
1.5 \mathrm{~g} \mathrm{~kg}^{-1}\end{array}$ & 2 months \\
\hline Ai et al. [35] & B. subtilis/FOS & $\begin{array}{l}\mathrm{C} \\
\mathrm{F}_{1} \\
\mathrm{~F}_{2} \\
\mathrm{~B}_{1} \\
\mathrm{~B}_{1} \mathrm{~F}_{1} \\
\mathrm{~B}_{1} \mathrm{~F}_{2} \\
\mathrm{~B}_{2} \\
\mathrm{~B}_{2} \mathrm{~F}_{1} \\
\mathrm{~B}_{2} \mathrm{~F}_{2}\end{array}$ & $\begin{array}{l}0 / 0 \\
0 / 0.2 \% \\
0 / 0.4 \% \\
0.42 \times 10^{7} / 0 \\
0.42 \times 10^{7} / 0.2 \% \\
0.42 \times 10^{7} / 0.4 \% \\
1.35 \times 10^{7} / 0 \\
1.35 \times 10^{7} / 0.2 \% \\
1.35 \times 10^{7} / 0.4 \%\end{array}$ & 10 weeks \\
\hline $\begin{array}{l}\text { Geng et al. } \\
\text { [36] }\end{array}$ & $\begin{array}{l}\text { B. subtilis/Chi- } \\
\text { tosan }\end{array}$ & $\begin{array}{l}\mathrm{C} \\
\mathrm{Ch}_{1} \\
\mathrm{Ch}_{2} \\
\mathrm{~B}_{1} \mathrm{Ch}_{1} \\
\mathrm{~B}_{1} \mathrm{Ch}_{2} \\
\mathrm{~B}_{2} \mathrm{Ch}_{1} \\
\mathrm{~B}_{2} \mathrm{Ch}_{2}\end{array}$ & $\begin{array}{l}0 / 0 \\
0 / 3 \mathrm{~g} \mathrm{~kg}^{-1} \\
0 / 6 \mathrm{~g} \mathrm{~kg}^{-1} \\
1 \mathrm{~g} \mathrm{~kg}^{-1} / 3 \mathrm{~g} \mathrm{~kg}^{-1} \\
1 \mathrm{~g} \mathrm{~kg}^{-1} / 6 \mathrm{~g} \mathrm{~kg}^{-1} \\
2 \mathrm{~g} \mathrm{~kg}^{-1} / 3 \mathrm{~g} \mathrm{~kg}^{-1} \\
2 \mathrm{~g} \mathrm{~kg}^{-1} / 6 \mathrm{~g} \mathrm{~kg}^{-1}\end{array}$ & 8 weeks \\
\hline
\end{tabular}

Bacterial genera abbreviations: E. = Enterococcus, B. = Bacillus.

Prebiotic abbreviations: PHB/P- plyhydroxybutyrate acid, MOS/M- Mannan oligosaccharide, FOS/F- fructooligosaccharide, Ch: chitosan.

Subindex numbers indicates different concentrations of administrated ingredient.

Table 2: Experimental diets and administration time evaluated in studies aimed on the effects of the administration of synbiotic in farmed fish. All the diets are explained in the text. the end of experimental period compared to those from the control. The highest average of survival rate was observed in the $T_{2}$ that was statistically different from $\mathrm{T}_{1}, \mathrm{~T}_{3}$ and the control groups.

In yellow croaker and cobia, administration of B. subtillis/FOS or B. subtillis/chitosan respectively, not affect the survival rate, with no differences among different dietary treatments $[35,36]$.

In terms of growth parameters, almost all references reported a positive effect of synbiotics on any parameter. Rainbow trout fed with diets M, EM and EMP recorded significantly higher weigh gain rate (WGR) and specific growth rate (SGR) than those of the rest experimental groups. Differences among experimental groups $\mathrm{E}$ and $\mathrm{P}$ were not significant with respect to the control group, whereas fish fed the EP diet showed significant better growth and SGR. In general, major effects were observed in EM and EMP, with no differences between the two groups [31]. These results suggest that dietary MOS significantly improved growth performance and nutrient utilization of fish, showing a synergist effect when administered combined with $E$. faecalis. Combination of E. faecalis and PHB slightly improved growth performance of rainbow trout.

In the Japanese flounder study [32], the control group exhibited the lowest final body weight (FBW) and WGR of all dietary treatments. Diets $\mathrm{M}, \mathrm{FM}, \mathrm{BM}$ and $\mathrm{BFM}$ increased FBW, whereas diets $\mathrm{MB}$ and BFM increased WGR $(P<0.05)$. However, there were no significant differences in FBW and WGR among any FOS, MOS and B. clausii treatments. In contrast, the fish that fed diets $\mathrm{M}, \mathrm{FM}, \mathrm{BF}, \mathrm{BM}$ or BFM had significantly lower feed conversion ratio (FCR) than those fed the control diet. These results showed that a single administration of FOS, MOS and B. clausii did not improve the WGR of the Japanese flounder compared with the control diet. Feeding FOS, MOS or B. clausii alone, or in various combinations, improved WGR and feed efficiency, which was more pronounced in fish fed the synbiotics than those fed prebiotics or probiotics alone.

The study of Mehrabi et al. [34] showed that after 60 days groups fed diets containing different levels of synbiotics $(0.5,1.0$ and 1.5$)$ increased body weight gain about 50, 59 and 53\%, respectively, in comparison with the control group. Even though, the highest average of final weight and weight gain was observed in group $\mathrm{T}_{2}$, however, there was no significant difference between $\mathrm{T}_{2}$ and $\mathrm{T}_{3}$. The addition of synbiotic to the feed also produced the better SGR, FCR and conversion factor (CF) with values significantly higher than the control, more specifically in groups treated with $0.1 \%$ synbiotic. In this study, significant better growth performance was observed in $O$. mykiss fingerlings maintained on the diet supplemented with synbiotic.

The results of the study carried out by Ai et al. [35] showed that at each dietary FOS level, dietary supplementation of $1.35 \times 10^{7} \mathrm{cfu} \mathrm{g}^{-1}$ $B$. subtilis significantly increased the SGR and feed efficiency ratio (FER) compared with the groups without $B$. subtilis supplementation. However, no significant differences were observed between the groups without $B$. subtilis and $0.42 \times 10^{7} \mathrm{cfu} \mathrm{g}^{-1} B$. subtilis group, and between the two B. subtilis-supplemented groups. In addition, at each B. subtilis level, dietary supplementation of FOS did not significantly affect the SGR, survival rate, FER and hepatosomatic index (HIS) of juvenile large yellow croaker. In this study, dietary supplementation of FOS did not exert beneficial effects on the growth performance, survival and feed utilization, and no significant interactions were observed between B. subtilis and FOS. The significantly enhanced SGR and FER by $B$. subtilis in this study clearly showed the growth improving property of B. subtilis. 
Results in cobia [36] showed that SGR in fish fed with dietary treatments was significantly higher than that of the control fish except diet 6 group, fed diet with $2.0 \mathrm{~g} \mathrm{~kg}^{-1}$ B. subtilis and $3.0 \mathrm{~g} \mathrm{~kg}^{-1}$ chitosan. At 1.0 and $2.0 \mathrm{~g} \mathrm{~kg}^{-1}$ supplemental B. subtilis, the cobia fed diets supplemented with $6.0 \mathrm{~g} \mathrm{~kg}^{-1}$ chitosan had significantly higher SGR than those fed diets supplemented with $3.0 \mathrm{~g} \mathrm{~kg}^{-1}$ chitosan. At 6.0 $\mathrm{g} \mathrm{kg}^{-1}$ supplemental chitosan, the cobia had significantly higher SGR in group fed diets supplemented with $1.0 \mathrm{~g} \mathrm{~kg}^{-1}$ supplemental B. subtilis. The significant and maximum SGR was observed in the fish fed with 1.0 $\mathrm{g} \mathrm{kg}^{-1}$ B. subtilis and $6.0 \mathrm{~g} \mathrm{~kg}^{-1}$ chitosan, suggesting the supplementation level was optimal for the growth of cobia.

Body composition has been analyzed by Rodriguez-Estrada et al. [31], Ye et al. [32] and Mehrabi et al. [34]. First of these studies, reported no significant differences in moisture, crude ash, crude lipids and crude proteins contents among all the experimental groups. However, in Japanese flounder there was an increase in body protein content in fish fed a FOS-, MOS- and/or B. clausii-containing diet compared to the control. Fish fed diets BF and BFM also exhibited significantly higher body protein content than fish fed the control diet.

Body lipid content demonstrated an opposite trend to body protein content, where fish fed diets $\mathrm{B}, \mathrm{MB}$ and $\mathrm{BFM}$ presented with significantly lower levels than fish fed the control diet. Neither body moisture nor ash content was affected by any dietary treatments [32]. In the same manner, the percentage of body protein in cobia fed with synbiotic was significantly higher than that from the control fish whereas the percentage of lipid, moisture and dry matter was not [34]. Higher body protein content in the treatment groups implies on this fact that by application of synbiotics, the ingested food was converted more effectively into the structural protein and subsequently resulted more muscle as it is a desirable aspect in fish farming.

\section{Effects of synbiotics on fish haematological and biochemical parameters}

Among the haematological and biochemical parameters evaluated in fish after treatments with synbiotics we find hematocrit, triglyceride (TG), cholesterol (CHO), low-density protein cholesterol (LDL-C), high-density protein cholesterol (HDL-C), total serum protein, albumin, globulin and glucose.

Rodriguez-Estrada and colleagues [31] found that hematocrit value was higher in the EM and EMP groups than the C, E, M, P, and EP groups, and significant higher hematocrit value was recorder in the $\mathrm{E}$ and $\mathrm{M}$ groups than the $\mathrm{C}$ and $\mathrm{P}$ groups.

Serum biochemical parameters evaluated by Ye et al. [32], reported the following results: The TG level was lower or tended to be lower in fish fed the FOS, MOS and/or B. clausii-containing diets versus the control diet. Diets supplemented with FOS, MOS and/or B. clausii, except diet $M$, significantly decreased TG levels compared with the control diet. By comparison, the TG level in fish fed diet FM was lower than in fish fed diet $\mathrm{M}$ but similar to the levels in fish fed diet. There were no differences in TG levels among diets BF, BM and BFM. The LDL-C response was similar to TG levels. However, feeding diets F, BF or BFM yielded significant decreases in LDL-C levels compared with the control diet. Significant differences were not observed in $\mathrm{CHO}$ or HDL-C levels among all dietary treatments.

Dietary administration of commercial symbiotic in rainbow trout resulted in an increase of total serum protein content in $\mathrm{T}_{2}$ and $\mathrm{T}_{3}$ treatments compared to other fed treatment and the control. In terms of albumin, only $\mathrm{T}_{2}$ showed a significant increase. Some other recorded parameters such as albumin/globulin ratio and triglycerides in fish fed with different levels of synbiotic did not show any significant difference in comparison with that from the control group at the end of the experiment. Furthermore, there was no significant difference between blood glucose in fish fed with different levels of synbiotic and control group, whereas this parameter was significantly different between $T_{1}$ and $\mathrm{T}_{3}$. The significant increase in total serum protein and albumin confirmed the involvement of synbiotic in triggering the immune system of rainbow trout following dietary administration [34].

\section{Effects of synbiotics on fish digestive enzyme activity}

Only one of these five studies has regarded the effect of synbiotic administration on digestive enzyme activity. Ye et al. [32], which evaluated the activities of amylase and protease, found that protease activity was significant higher in fish fed diets BM and BFM than in fish fed the control diet, obtaining similar value in both diets. No any other supplementation could positively affect the protease activity. These results indicated that administration of FOS in combination with MOS and $B$. clausii not determine a major increase in protease activity than the observed with the BM diet.

Moreover, fish fed the diet BFM exhibited the highest amylase activity, which was significantly higher than in fish fed diets FM, B, and control diets.

The increase in digestive enzyme activities would allows the host degrades more nutrients, improving digestion and promoting a possible increase in the WGR and/or feed efficiency.

\section{Effects of synbiotics on fish immune system}

Among the studies carried out about synbiotics in fish, four of them have evaluated the effect on immune system, analyzing different activities such as lysozyme, alternative complement pathway, phagocytosis, respiratory burst, superoxide dismutase and mucus production.

Lysozyme activity: Lysozyme is one of the important bactericidal enzymes of innate immunity, and constitutes an essential defence mechanism against pathogens in fish [37]. The study of Ye et al. [32] on Japanese flounder revealed that dietary treatments affected lysozyme activity differently. This activity was significantly higher in fish fed diets $\mathrm{B}, \mathrm{BF}, \mathrm{BM}$ and BFM compared with those fed the control diet, however there was no significant difference in lysozyme activity between diets F, M and FM and between diets FB, MB and FMB. Therefore, the study concludes that feeding B. clausii promoted lysozyme activity. Moreover, lysozyme activity was significantly higher in fish fed a symbiotic diet than in those fed diets supplemented with the individual prebiotics and tended to enhance activity compared to those fed the B. clausii diet, which suggests that the dietary administration of FOS or/and MOS combined with $B$. clausii synergistically modulates lysozyme activity.

These results contrast with those obtained in yellow croaker by Ai et al. [35], in which no synergic effect was observed with FOS and $B$. subtilis administration. In this study, the serum lysozyme activities in fish fed $\mathrm{B}_{1}, \mathrm{~B}_{1} \mathrm{~F}_{1}, \mathrm{~B}_{1} \mathrm{~F}_{2}, \mathrm{~B}_{2}, \mathrm{~B}_{2} \mathrm{~F}_{1}$, and $\mathrm{B}_{2} \mathrm{~F}_{2}$ diets were significantly higher than fish fed control, $F_{1}$ or $F_{2}$ diets, while no significant differences were observed between the two dietary $B$. subtilis levels. These results showed that lysozyme activity increase could be independent of FOS, being a response to $B$. subtilis. Although no significant differences were observed between the two dietary $B$. subtilis levels, a tendency was observed towards major activity with major B. subtilis concentration.

Geng et al. [36] observed that chitosan at $6.0 \mathrm{~g} \mathrm{~kg}^{-1}$ significant 
increases lysozyme activity when administered alone or in combination with $B$. subtilis at any of the two levels. No significant differences were observed among groups fed diets with $3.0 \mathrm{~g} \mathrm{~kg}^{-1}$ chitosan with respect to control diet. Fish fed diets supplemented with high chitosan level $(6.0 \mathrm{~g}$ $\mathrm{kg}^{-1}$ ) had higher serum lysozyme activities than those fed the basal diet and diets supplemented with low chitosan level $\left(3.0 \mathrm{~g} \mathrm{~kg}^{-1}\right)$ regardless of $B$. subtilis levels. At the same chitosan level, no significant differences were observed among $B$. subtilis levels, suggesting the serum lysozyme activity was not affected by dietary $B$. subtilis.

Alternative complement pathway activity: This activity has been only evaluated in yellow croaker and cobia, following to administration of $B$. subtilis, combined with FOS or chitosan respectively $[35,36]$. In yellow croaker, ACP activity was not significantly affected by the proand prebiotics supplementation. In cobia, this activity was significant enhanced with diets supplemented with low chitosan level $\left(3.0 \mathrm{~g} \mathrm{~kg}^{-1}\right)$ at any B. subtilis level, whereas the high chitosan level $\left(6.0 \mathrm{~g} \mathrm{~kg}^{-1}\right)$ only produces an increase in ACP when administered with B. subtilis at 2.0 $\mathrm{g} \mathrm{kg}^{-1}$. However, no significant differences were observed among groups fed with $B$. subtilis $2.0 \mathrm{~g} \mathrm{~kg}^{-1}+$ chitosan $3.0 \mathrm{~g} \mathrm{~kg}^{-1}$ and those fed with $B$. subtilis $2.0 \mathrm{~g} \mathrm{~kg}^{-1}+$ chitosan $6.0 \mathrm{~g} \mathrm{~kg}^{-1}$.

Superoxide dismutase activity: In the yellow croaker study by Ai et al. [35] at each FOS level, serum SOD activity was significantly enhanced by the supplementation of $1.35 \times 10^{7} \mathrm{cfu} \mathrm{g}^{-1} B$. subtilis and there were no significant differences between the $B$. subtilis-deficient group and the $0.42 \times 10^{7} \mathrm{cfu} \mathrm{g}^{-1} B$. subtilis group, and between the two $B$. subtilis supplemented groups. These results seem to indicate than increase in this activity occurs in response to B. subtilis, and discard a synergic effect of this symbiotic.

Phagocytic activity: Phagocytic activity has been evaluated in various studies. Rodriguez-Estrada et al. [31] demonstrated that phagocytic activity and index in the E, M, EM and EMP groups were significantly higher than that of the $\mathrm{C}$ group. Major increment was observed in EM and EMP groups, without differences between both treatments or between groups $\mathrm{E}$ and $\mathrm{M}$. This suggests that PHB does not affect phagocytic activity, and reveals again a synergic effect of $E$. faecalis and MOS when administered together.

However, Ye and colleagues [32] report that phagocytic percentage and index of leucocytes in fish fed diets supplemented with FOS, MOS and/or B. clausii, were similar to those of fish fed the control diet. The study carried out by Geng et al. [36] indicates that at all experimental diets, except chitosan at $6.0 \mathrm{~g} \mathrm{~kg}^{-1}$, significantly enhances phagocytic percentage with respect to the control diet. At any of the levels of $B$. subtilis, phagocytic percentage in fish fed diets with $3.0 \mathrm{~g} \mathrm{~kg}^{-1}$ chitosan were higher than that in the groups fed diets with $6.0 \mathrm{~g} \mathrm{~kg}^{-1}$ chitosan, and there was only statistically significant difference at $2.0 \mathrm{~g} \mathrm{~kg}^{-1} B$. subtilis level. At any of the two levels of chitosan, phagocytic percentage significantly increased with the increase of $B$. subtilis supplementation level. Major effect was observed with chitosan at $3.0 \mathrm{~g} \mathrm{~kg}^{-1}$ and $B$. subtilis at $2.0 \mathrm{~g} \mathrm{~kg}^{-1}$. These results reveal a synergic effect of chitosan and $B$. subtilis when administered together in adequate amounts.

Respiratory burst activity: The respiratory burst of head kidney leucocytes were not affected by dietary administration of FOS and $B$. subtilis in yellow croaker [35]. However, following to administration of chitosan and B. subtilis in cobia [36] this activity was significant enhanced by dietary treatments except the group fed high level chitosan $\left(6.0 \mathrm{~g} \mathrm{~kg}^{-1}\right)$. When administered at low level $\left(3.0 \mathrm{~g} \mathrm{~kg}^{-1}\right)$ chitosan enhances respiratory burst single or with any of $B$. subtilis level, and present a maximum with $B$. subtilis at low concentration. When administered at high level $6.0 \mathrm{~g} \mathrm{~kg}^{-1}$, chitosan exert a possitive effect on respiratory burst if is combined with any level of $B$. subtilis. These results remark the synergistic activity of both prebiotic and probiotic.

Mucus production: Mucus is the first physical barrier that inhibits entry of disease organisms from the environment into the fish. It is also a chemical barrier, containing enzymes and antibodies which can kill invading disease organisms. Mucus also lubricates the fish, aiding their movement through water, and is important for osmoregulation [38]. Rodriguez-Estrada et al. [31] demonstrated that dietary E. faecalis, MOS and PHB in rainbow trout increase significantly mucus production in fish fed E, M, EM and EMP than that of the group C.Major increment was observed in EM and EMP groups, without differences between both treatments.

\section{Effects of synbiotics on fish disease resistance}

As synbiotic therapy may offer a suitable alternative for controlling pathogens, the effectiveness of synbiotics in terms of protection against infectious agents could be evaluated by a challenge test. To date, challenge test carried out in fish following to symbiotic administration, have employed Vibrio sp species as pathogens, specifically $V$. anguillarum and $V$. harveyi $[32,35,36]$.

In 2009, Rodriguez-Estrada et al. [31] carried out for first time a challenge test in fish feed with synbiotics during 12 weeks. After $14 \mathrm{dpi}$ with $V$. anguillarum all groups showed lower mortality than that control group, being significant in EM and EMP groups.

Dietary B. subtilis supplementation $\left(1.35 \times 10^{7} \mathrm{cfu}^{-1}\right)$ in yellow croaker [35] during 10 weeks elevated the resistance to $V$. harveyi infection, but this response was not related with presence or concentration of FOS. No significant interactions were observed between dietary B. subtilis and FOS in the cumulative mortality after challenge.

In Geng et al. [36] cobia fed diets supplemented with various levels of probiotic and chitosan for 56 days were challenged with $V$. harveyi. Post-challenge survival of fish was always significantly higher in high chitosan groups and increased at each chitosan level with the increase of $B$. subtilis supplementation level, which speculated chitosan and $B$. subtilis have a synergistic effect.

\section{Conclusions}

In recent years, probiotics and prebiotics have become an integral parts of the aquaculture practices for improving the growth performance and disease resistance [10,21]. Many studies revealed the effects of probiotics to improve feed conversion, growth rates, weight gain, immune system and disease resistance of fish [10,11,20], whereas the effects of prebiotics on these and other parameters have been investigated to a limited extent in different species [18,21]. However, given the progress of previous studies it is clear that biotic applications are useful tools for improving the health status and production of fish, in place of more established immunological and disease control methods as vaccinations, antimicrobials and immunostimulants.

Combined application of probiotics and prebiotics, known as synbiotics, is based on the principle of providing a probiont with a competitive advantage over endogenous populations, improving the survival and implantation of the live microbial dietary supplement in the gastrointestinal tract of the host [12]. The use of synbiotics may make possible to produce greater benefits than the application of individual probionts [20]. 


\begin{tabular}{|c|c|c|c|}
\hline Reference & Fish species & Probiotic/prebiotic & Results \\
\hline $\begin{array}{l}\text { Rodriguez-Estrada } \\
\text { et al [31] }\end{array}$ & O. mykiss & $\begin{array}{l}\text { E. faecalis/MOS, } \\
\text { PHB }\end{array}$ & $\begin{array}{l}\uparrow \text { body weight, } \\
\text { SGR, hematocrit } \\
\text { value, phagocytic } \\
\text { activity, phago- } \\
\text { cytic index, mucus } \\
\text { production, } \downarrow \\
\text { mortality. }\end{array}$ \\
\hline Ye et al [32] & P. olivaceus & $\begin{array}{l}\text { B. clausii/MOS, } \\
\text { FOS }\end{array}$ & $\begin{array}{l}\uparrow \text { body weight, } \\
\text { WGR, } \downarrow \text { FCR, CF, } \uparrow \\
\text { crude protein and } \\
\text { lipid, } \uparrow \text { lisozime, } \\
\downarrow T G \text { and LDL-C, } \\
\uparrow \text { protease and } \\
\text { amylase activities }\end{array}$ \\
\hline Mehrabi et al [34] & O. mykiss & $\begin{array}{l}\text { Biomin IMBO (E. } \\
\text { faecium/FOS) }\end{array}$ & $\begin{array}{l}\uparrow \text { body weight, } \\
\text { body wieght gain, } \\
\text { SGR, FCE, SR, } \\
\uparrow \text { crude protein, } \uparrow \\
\text { serum protein. }\end{array}$ \\
\hline Ai et al [35] & L. crocea & B. subtilis/FOS & $\begin{array}{l}\uparrow \text { SGR, FER, } \\
\text { lisozime, SOD, } \downarrow \\
\text { mortality. }\end{array}$ \\
\hline Geng et al [36] & R. canadum & B. subtilis/Chitosan & $\begin{array}{l}\uparrow \text { SGR, lisozime, } \\
\text { ACP, phacocytosis, } \\
\text { respiratory burst, } \downarrow \\
\text { mortality. }\end{array}$ \\
\hline
\end{tabular}

Fish genera abbreviations: O. = Onchorhynchus, P. = Paralichtys, L. = Larimich thys, R. = Rachycentron.

Bacterial genera abbreviations: E. = Enterococcus, B. = Bacillus

Prebiotic abbreviations: PHB- plyhydroxybutyrate acid, MOS- Mannan oligosaccharide, FOS- fructooligosaccharide.

SGR: specific growth rate, WGR: weight gain rate, FCR: feed conversion ratio; CF: condition factor; FER: feed efficiency ratio; TG: triglicerides, LDL-C: low-density lipoprotein cholesterol, SOD: superoxide-dismutase, ACP: alternative complement pathway.

Table 3: Summary of results obtained in fish synbiotic studies.

Studies considered in this review reveal different effects of synbiotics on regarded species (Table 3). On this way, RodriguezEstrada et al. [31] concludes that dietary incorporation of MOS in a single or a combined inclusion with $E$. faecalis, enhances the rainbow trout growth and activates its immune system, whereas in japanese flounder the authors did not observe a clear synergistic effect when we compared the combination feeding to feeding prebiotics (MOS, FOS) and probiotics (B. clausii) alone [32]. Results of this study are accordingly with obtained by Ai et al. [35] This study demonstrates that administration of $B$. subtilis enhanced not only the growth performance and feed utilization of juvenile large yellow croaker, but also the non-specific immune responses and disease resistance. However, no significant interactions between dietary $B$. subtilis and FOS were observed, suggesting no synergic effect of these pre and probiotic under the experimental conditions. For last, Geng et al. [36] concludes that diet supplemented with the right level of chitosan and B. subtilis significantly enhanced the growth, innate immunity and protection against infection for cobia, and establish the optimal combination of both ingredients for the assayed conditions and parameters.

Dietary administration of a commercial synbiotic in Mehrabi et al. [34] has demonstrates an increase in the growth performances, survival rate, serum protein and albumin content, and improved feeding efficiency in rainbow trout. However, this study does not evaluate the capacity of pre and probiotic contained in synbiotic when administered single, so not allow consider the synergic properties of both ingredients.

In conclusion, considerable variation in growth, feed utilization and health benefits with the dietary use of prebiotics and/or probiotics is likely dependent on the fish species, feeding duration and supplement dose as well as the type of prebiotics and probiotics tested. Moreover, aspects such as effects on gut microbiota, mucosal barriers, cell damage/morphology, and mechanisms which mediate host benefits remain unclear. Therefore, further studies regarding the application of synbiotics in aquatic animals, especially their appropriate inclusion levels in specific species and specific rearing conditions, are needed to obtain the expected responses in fish.

\section{Acknowledgements}

This work was partly supported by national (Ministerio de Ciencia e Innovación AGL2008-05119-C02-01) and regional (Fundación Séneca, 04538/GERM/06) projects.

\section{References}

1. Rombout JH, Abelli L, Picchietti S, Scapigliati G, Kiron V (2010) Teleost intestinal immunology. Fish Shellfish Immunol 31: 616-626.

2. Das S, Ward LR, Burke C (2008) Prospects of using marine Actinobacteria as probiotics in aquaculture. Appl Microbiol Biotechnol 81: 419-429.

3. Mehrim Al (2009) Effect of dietary supplementation of Biogen® (Commercial probiotic) on mono-sex Nile tilapia Oreochromis niloticus under different stocking densities. J Fisher Aquat Sci 4: 261-273.

4. Mishra S, Mohanty S, Pattnaik P, Ayyappan S (2001) Probiotics: possible application in aquaculture. Fish Chimes 21: 31-37.

5. Sahu MK, Swarnakumar NS, Sivakumar K, Thangaradjou T, Kannan L (2008) Probiotics in aquaculture: importance and future perspectives. Ind J Microbiol 48: 299-308.

6. Irianto A, Austin B (2002) Probiotics in aquaculture. J Fish Dis 25: 633-642.

7. Vershuere L, Rombaut G, Sorgeloos P, Verstraete W (2000) Probiotic bacteria as biological control agents in aquaculture. Microbiol Mol Biol Rev 64: 655-671.

8. Fuller R (1989) Probiotics in man and animals. J Appl Bacteriol 66: 365-378.

9. Gatesoupe FJ (2008) Updating the importance of lactic acid bacteria in fish farming: natural occurrence and probiotic treatments. J Mol Microbiol Biotechnol 14: 107-114

10. Nayak SK (2010) Probiotics and immunity: a fish perspective. Fish Shellfish Immunol 29: 2-14.

11. Dimitroglou A, Merrifield DL, Carnevali O, Picchietti S, Avella M, et al. (2011) Microbial manipulations to improve fish health and production--a Mediterranean perspective. Fish Shellfish Immunol 30: 1-16.

12. Gibson GR, Roberfroid MB (1995) Dietary modulation of the human colonic microbiota: introducing the concept of prebiotics. J Nutr 125: 1401-1412.

13. Yazawa K, Imai K, Tamura Z (1978) Oligosaccharides and polysaccharides specifically utilisable by bifidobacteria. Chem Pharm.Bull 26: 3306-3311.

14. Gibson GR, Rastall RA, Fuller R (2003) The health benefits of probiotics and prebiotics. In: Fuller R, Perdigón G (Eds), Gut Flora, Nutrition, Immunity and Health. Blackwell Publishing Ltd, Oxford, UK, pp. 52-76.

15. Mahious AS, Ollevier F (2005) Probiotics and Prebiotics in Aquaculture. 1st Regional Workshop on Techniques for Enrichment of Live Food for Use in Larviculture-2005, AAARC, Urmia, Iran. p. 67.

16. Fooks LJ, Fuller R, Gibson GR (1999) Prebiotics, probiotics and human gut microbiology Int Dairy J 9: 53-61.

17. Gibson GR, Probert HM, Van Loo J, Rastall RA, Roberfroid MB (2004) Dietary modulation of the human colonic microbiota: Updating the concept of prebiotics. Nutr Res Rev 17: 259-275.

18. Yousefian M, Amiri MS (2009) A review of the use of prebiotic in aquaculture for fish and shrimp. Afr J Biotechnol 8: 7313-7318.

19. Roberfroid M (2007) Prebiotics: the concept revised. J Nutr 137: 830S-837S

20. Merrifield DL, Dimitroglou A, Foey A, Davies SJ, Baker RTM, et al. (2010) The current status and future focus of probiotic and prebiotic applications for salmonids. Aquaculture 302: 1-18

21. Ringø E, Olsen R, Gifstad T, Dalmo R, Amlund H, et al. (2010) Prebiotics in aquaculture: a review. Aquac Nutr 16: 117-136. 
Citation: Cerezuela R, Meseguer J, Esteban MA (2011) Current Knowledge in Synbiotic Use for Fish Aquaculture: A Review. J Aquac Res Development S1:008. doi:10.4172/2155-9546.S1-008

22. Burr G, Hume M, Ricke S, Nisbet D, Gatlin D III (2010) In vitro and in vivo evaluation of the prebiotics GroBiotic-A, inulin, mannanoligosaccharide, and galactooligosaccharide on the digestive microbiota and performance of hybrid striped bass (Morone chrysops x Morone saxatilis). Microb Ecol 59: 187-198.

23. Ibrahem MD, Fathi M, Mesalhy S, Abd El-Aty AM (2010) Effect of dietary supplementation of inulin and vitamin $\mathrm{C}$ on the growth, hematology, innate immunity, and resistance of Nile tilapia (Oreochromis niloticus). Fish Shellfish Immunol 29: 241-246.

24. Sherman PM, Ossa JC, Johnson-Henry K (2009) Unraveling Mechanisms of Action of Probiotics. Nutr Clin Pract 24: 10-14.

25. Quigley EM (2010) Prebiotics and probiotics; modifying and mining the microbiota. Pharmacol Res 61: 213-218.

26. Seifert S, Watzl B (2007) Inulin and Oligofructose: Review of Experimental Data on Immune Modulation. J Nutr 137: 2563S-2567S.

27. Magnadottir B (2010) Immunological control of fish diseases. Mar Biotechno 12: $361-379$

28. Chou T-C, Rideout D, Chou J, Bertino JR (1991) Chemotherapeutic synergism, potentiation and antagonism. In: Dulbecco R (Ed), Encyclopedia of human biology, vol. 2. Academic Press, San Diego, California, pp. 371-379.

29. Hagi T, Hoshino T (2009) Screening and characterization of potential probiotic lactic acid bacteria from cultured common carp intestine. Biosci Biotechnol Biochem 73: 1479-1483.

30. Lauzon HL, Gudmundsdottir S, Steinarsson A, Oddgeirsson M, Petursdottir SK et al. (2010) Effects of bacterial treatment at early stages of Atlantic cod (Gadus morhua L.) on larval survival and development. J Appl Microbiol 108: 624-632.

31. Rodriguez-Estrada U, Satoh S, Haga Y, Fushimi H, Sweetman J (2009)
Effects of single and combined supplementation of Enterococcus faecalis, mannanoligosaccharide and polyhydrobutyric acid on growth performance and immune response of rainbow trout Oncorhynchus mykiss. Aquacult Sci 57: $609-617$

32. Ye JD, Wang K, Li FD, Sun YZ (2011) Single or combined effects of fructoand mannan oligosaccharide supplements and Bacillus clausii on the growth feed utilization, body composition, digestive enzyme activity, innate immune response and lipid metabolism of the Japanese flounder Paralichthys olivaceus. Aquac Nutr 17: 902-911

33. Sun Y, Yang H, Ling Z, Chang J, Ye J (2009) Gut microbiota of fast and slow growing grouper Epinephelus coioides. Afr J Microbiol Res 3: 713-720.

34. Mehrabi Z, Firouzbakhsh F, Jafarpour A(2011) Effects of dietary supplementation of synbiotic on growth performance, serum biochemical parameters and carcass composition in rainbow trout (Oncorhynchus mykiss) fingerlings. $J$ Anim Physiol Anim Nutr (Berl) 24: doi: 10.1111/j.1439-0396.2011.01167.x.

35. Ai Q, Xu H, Mai K, Xu W, Wang J, et al. (2011) Effects of dietary supplementation of Bacillus subtilis and fructooligosaccharide on growth performance, survival, non-specific immune response and disease resistance of juvenile large yellow croaker, Larimichthys crocea. Aquaculture 317: 155-161.

36. Geng X, Dong XH, Tan BP, Yang QH, Chi SY, et al. (2011) Effects of dietary chitosan and Bacillus subtilis on the growth performance, non-specific immunity and disease resistance of cobia, Rachycentron canadum. Fish Shellfish Immunol 31: 400-406.

37. Lindsay GJH (1986) The significance of chitinolytic enzymes and lysozyme in rainbow trout (Salmo gairdneri) defence. Aquaculture 51: 169-173.

38. Shephard KL (1994) Functions for fish mucus. Review in Fish Biol and Fisheries. 4: 401-429.
This article was originally published in a special issue, Probiotic \& Prebiotic Applications in Aquaculture handled by Editor(s). Dr. Daniel L. Merrifield, University of Plymouth, UK; Prof. Zhigang Zhou, Chinese Academy of Agricultural Sciences, China 